\title{
Monitoring Training Load and Fatigue in Rugby Sevens Players
}

\author{
Mohamed Elloumi ${ }^{1,2,3^{*}}$, PhD; Emna Makni ${ }^{2}$, PhD; Wassim Moalla ${ }^{2,4}$, PhD; \\ Taieb Bouaziz ${ }^{2}$, MSc, PhD; Zouhair Tabka ${ }^{2}$, MD, PhD; Gérard Lac ${ }^{1}$, PhD; Karim Chamari ${ }^{3,5}$, PhD
}

\author{
Authors' Affiliation: \\ 1. Clermont University Blaise Pascal, \\ Laboratory AME2P, France \\ 2. Laboratory of Cardio-circulatory, \\ Respiratory, and Hormonal \\ Adaptations to Muscular Exercise, \\ Faculty de Medicine Sousse, Tunisia \\ 3. ISSEP-High Institute of Sport and \\ Physical Education Ksar Saïd, \\ University of Manouba, Tunis, \\ Tunisia \\ 4. UR EM2S, High Institute of Sport \\ and Physical Education Sfax, \\ University of Sfax, Tunisia \\ 5. Laboratory of "Sport Performance \\ Optimisation", National Centre of \\ Medicine and Science in Sports, \\ University of Tunis, Tunis, Tunisia \\ * Corresponding Author; \\ Address: Laboratory of Cardio- \\ circulatory, Respiratory, and Hormonal \\ Adaptations to Muscular Exercise, \\ Faculty of Medicine Ibn El Jazzar, \\ Sousse, Tunisia \\ E-mail: elloumimed@yahoo.fr
}

Received: Mar 24, 2012

Accepted: May 29, 2012

Key Words: Training Load; Performance; Score of Fatigue; Rugby Sevens

\begin{abstract}
Purpose: Trainers and physical fitness coaches' need a useful tool to assess training loads to avoid overtraining. However, perceived scales or questionnaires were required. Therefore, the purpose of this study was to assess whether a short 8-item questionnaire of fatigue could be a useful tool for monitoring changes in perceived training load and strain among elite rugby Sevens (7s) players during preparation for a major competition.
\end{abstract}

Methods: Sixteen elite rugby 7 s players completed an 8-week training program composed of 6-week intense training (IT) and 2-week reduced training (RT). They were tested before (T0), after the IT (T1) and after the RT (T2). The quantification of the perceived training load and strain were performed by the session-RPE (rating of perceived exertion) method and concomitantly the 8-item questionnaire of fatigue was administered.

Results: Training load (TL) and strain (TS) and total score of fatigue (TSF from the 8-item questionnaire) increased during IT and decreased during RT. Simultaneously, physical performances decreased during IT and were improved after LT. The changes in TL, TS and TSF correlated significantly over the training period $(\mathrm{r}=\mathbf{0 . 6 3 - 0 . 8 3})$.

Conclusions: These findings suggest that the short questionnaire of fatigue could be a practical and a sensitive tool for monitoring changes in training load and strain in team-sport athletes. Accordingly, the simultaneous use of the short questionnaire of fatigue along with the session-RPE method for perceived changes in training load and strain during training could provide additional information on the athletes' status, allowing coaches to prevent eventual states of overreaching or overtraining.

Asian Journal of Sports Medicine, Volume 3 (Number 3), September 2012, Pages: 175-184

\section{INTRODUCTION}

$\mathrm{R}$ ugby union is a competitive ball game usually practiced by 15 players per team and considered as physically demanding sport requiring players to participate in frequent bouts of intense activity such as sprinting, physical collisions, and tackles separated by short bouts of low intensity activity such as walking and jogging ${ }^{[1]}$. As a result, rugby players must draw upon several high level fitness components including muscular power, speed, agility, and aerobic power ${ }^{[1,2]}$. Rugby Sevens $(7 \mathrm{~s})$ is played with seven players on a regular rugby pitch and derived from the original game of rugby. After several years of rugby $7 \mathrm{~s}$ World cups, the International Olympic Community has recently integrated this game as an Olympic sport for the 2016 Olympics. The basic rules of Sevens, including the size of the pitch, are the same as for an ordinary rugby match, except for shorter match duration, i.e. tw0 7min half times with only 1-min recovery in-between. As rugby $7 \mathrm{~s}$ players must play on a full-sized pitch, it follows that they have a potentially higher exercise loading than under the conditions of a normal rugby Union or even rugby league game. Usually, more than 
two games are held on the same day with only few hours of recovery in-between leading to the fact that it is assumed that rugby $7 \mathrm{~s}$ players experience high levels of psychological and physiological stress with respect to rugby union ${ }^{[3]}$. Furthermore, during a $7 \mathrm{~s}$ tournament, the cumulative effect of exercise loading is thought to be hard, similar to that experienced during strenuous anaerobic exercise training ${ }^{[3]}$. In this context, rugby $7 \mathrm{~s}$ training develops the physical requisites for competition and consists of a high volume of resistance training and anaerobic and aerobic conditioning, which leads to high levels of perceived fatigue ${ }^{[4]}$.

The obvious goal of athletic training is to enhance or to maintain physical performances. It requires an optimal training program based on an adequate balance between training volume and intensity and rest periods. When training is prolonged, excessive stress is applied concurrently with possible inadequate recovery. In this case, many of the positive physiological adjustments associated with physical training are reversed, reaching states of overreaching or overtraining and leading to chronic maladaptations and performance decrements $[5,6]$. To prevent overtraining and to ensure that the athletic training program will result in performance improvements, or at least the maintenance of performance standards, it is indicated to include regular performance tests as a component of the training program. In addition, to assess the effectiveness of the training process, sports coaches are required to monitor training load (TL) and training strain (TS). In this context, numerous methods and strategies have been proposed to monitor the training status of athletes in a practical manner, with a goal of appropriately adjusting TL and TS ${ }^{[7-10]}$. The most widely used methods for evaluating internal training load use heart rate (HR) as a measure of exercise intensity ${ }^{[8]}$. However, the application of HR as a measure of exercise intensity has several limitations especially during weight, interval, intermittent and plyometric training ${ }^{[7]}$. In the last decade, the session-rating of perceived exertion (RPE) method for quantifying training load and strain has become a popular tool for monitoring training periodization in various sports ${ }^{[9,10]}$. This method is simple, practical and validated in several individual and team sports ${ }^{[7,9,10]}$.

Additionally, it is widely admitted that psychological factors, such as training stress and anxiety, may play a crucial role in high-level sporting performance especially while they interfere with the daily extrasports constraints ${ }^{[6]}$. Psychological measures have been proven to be as effective as physical measures in diagnosing training stress ${ }^{[11]}$. Consequently, several psychological questionnaires have been employed for monitoring changes in training stress, strain and recovery with the aim of detecting early signs of tiredness and/or overtraining [11-14]. Accordingly, Chatard et $\mathrm{al}^{[12]}$ have proposed in an alternative approach, "the short questionnaire of fatigue" which stems from the large questionnaire of the "French Society for Sports Medicine" ${ }^{,[14]}$. It is an attractive questionnaire which consists of eight-items focused on the perception of training, sleep, leg pain, infection, concentration, efficacy, anxiety, irritability, and general stress. In addition, this questionnaire of fatigue was validated as a very sensitive tool to the variations of training load and performances in swimmers ${ }^{[15]}$. However, no data are available on the variation of this questionnaire's results during intense training in teamsports athletes. Additionally, to the best of our knowledge, the monitoring of training load and strain in rugby $7 \mathrm{~s}$ players during training has never been carried out. Therefore, the aim of the present study was to investigate whether the short 8-item questionnaire of fatigue could be a useful tool for monitoring perceived training load and strain and performance responses in elite rugby $7 \mathrm{~s}$ players during the preparation for a major competition.

\section{METHODS AND SUBJECTS}

\section{Participants:}

Sixteen players from the 7s Tunisian national rugby team volunteered to participate in this study. After being informed about the experimental procedures, subjects agreed to participate in this work and filled a written informed consent form. The study protocol which was in accordance with the Declaration of Helsinki 1975 was approved by the University Ethical Committee. All players regularly participated in national and international competitions. They were training with their clubs on average 5 to 6 times per week, i.e. 10 to 12 hours weekly. In the preparation 
periods to international meetings, they used to train with the national team twice a day from Monday to Friday, with a corresponding training volume of 3 to 4 hours per day in addition to two $7 \mathrm{~s}$ rugby games played in the weekend. Moreover, these players participated in five $7 \mathrm{~s}$ World Tour tournaments per year which were organized by the International Rugby Board. The dietary intake was assessed and administrated by nutritionist who supervises all nutritional menus for the players. None of the subjects were taking medication or did exhibit metabolic and/or endocrine dysfunctions that could impede or limit their ability to fully participate in the study. The study was conducted during the preparation period for the $7 \mathrm{~s}^{\prime}$ World Cup organized in March in Dubai.

\section{Procedures:}

The present study was completed between December 2008 and March 2009. Anthropometric measurements and physical tests were performed three times, at the same time of the day, at the National Center of Medicine and Science in Sports, Tunis (temperature: $18 \pm 2{ }^{\circ} \mathrm{C}, 44 \pm 8 \%$ relative humidity): 1) before the start of the training program (T0), 2) After an intense 6-week training period (IT) or overload (T1) and 3) After a 2-week period of reduced training (RT) or taper (T2). These tests were part of the prospect of controlling the players' fitness level for a tournament that was part of the 7s' World Cup (Fig. 1).

Body mass and height were measured with calibrated devices (Tanita, SC-330-S model, accuracy 100gr, and Harpenden Portable Stadiometer, accuracy $1 \mathrm{~mm}$, respectively)

The Body Mass Index $[\mathrm{BMI}=$ weight $(\mathrm{kg}) /$ height (m2)] was calculated. Percentage of body fat (\% BF) was estimated from four skinfolds (supra-iliac, biceps, triceps, and sub-scapular) using the formula of Durnin and Womersley ${ }^{[16]}$. The measurement of these skinfolds was conducted by a clamp mark Harpenden caliper (Holtain Ltd Bryberian, UK).

\section{Physical performance testing:}

During the period of training familiarization, all physical testing was performed individually on two occasions at least $72 \mathrm{~h}$ apart to establish test-retest reproducibility. Following, subjects were assessed three times (T0, T1, and $\mathrm{T} 2$ ) during the training period by the means of tests that reflect the different qualities sought in a rugby competition. Tests assessed speed, power, legs explosiveness, and agility, along with aerobic and anaerobic capacities.

The players performed three maximal $30-\mathrm{m}$ sprints with intermediate 10 and $20-\mathrm{m}$ split times on an indoor synthetic court ${ }^{[17]}$. The reliability of $10-\mathrm{m}(\mathrm{ICC}=0.93$, $\mathrm{SEM}=0.05), 20-\mathrm{m}(\mathrm{ICC}=0.94, \mathrm{SEM}=0.05)$ and $30-\mathrm{m}$ ( $\mathrm{ICC}=0.87, \mathrm{SEM}=0.09)$ sprint tests were high.

The five-jump test (5JT) consisting of 5 consecutive strides and assessing lower limbs power was administered ${ }^{[18]}$. The reliability of the $5 \mathrm{JT}$ was high $(\mathrm{ICC}=0.92, \mathrm{SEM}=0.78)$ and similar to that previously reported by Chamari et al ${ }^{[18]}$ for elite-level male soccer players.

Agility was assessed using the agility test (AGT) "Illinois agility run" ${ }^{[2]}$. During the 2-3 min recovery period in-between, players walked back to the starting line and then waited for the next sprint. Timing was automatically recorded using photocell gates (Brower Timing Systems, Salt Lake City, Utah, USA, accuracy

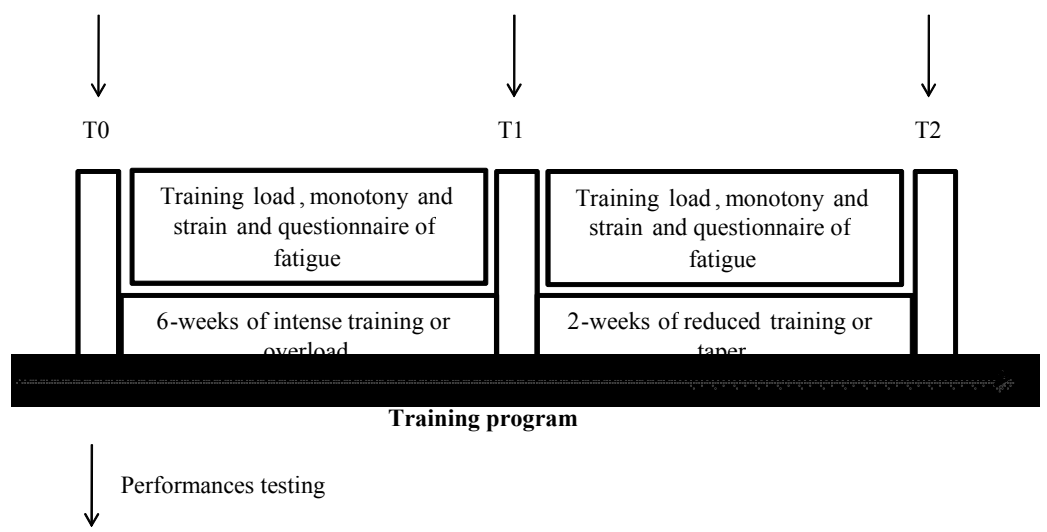

Fig. 1: Study design: training load, monotony and strain, questionnaire of fatigue and timing of testing performances 
of $0.01 \mathrm{~s}$ ) placed $0.4 \mathrm{~m}$ above the ground. The reliability of the AGT was high (ICC $=0.89$, $\mathrm{SEM}=0.43$ ).

The lactic anaerobic capacity was assessed using the lactic test (LT) "Australian lactic test" according to the protocol described by Maso et al ${ }^{[19]}$. The reliability of the LT was high $(\mathrm{ICC}=0.98$, SEM=15.03).

Aerobic capacity was assessed using the Yo-Yo intermittent recovery test level 2 (Yo-Yo IRT2) according to the protocol proposed by Krustrup et al ${ }^{[20]}$. It has been shown that the performance achieved in Yo-Yo IRT 2 is strongly correlated with maximal oxygen uptake $\left(\mathrm{VO}_{2 \max }\right)^{[20]}$. The reliability of the YoYo IRT2 was high $(\mathrm{ICC}=0.99, \mathrm{SEM}=159.68)$.

Tests were performed over two days with 5 min of recovery in-between in the following order: $1^{\text {st }}$ day, maximal 30-m sprints, 5JT, AGT and LT; $2^{\text {nd }}$ day, YoYo IRT2).

Each participant was instructed and verbally encouraged to give a maximal effort during all tests. Additionally, all physical tests were performed on an indoor handball court by the same investigator throughout the study.

\section{Training load monitoring:}

Training load, monotony, and strain for each participant were calculated according to the sessionRPE method of Foster et al ${ }^{[7]}$. Throughout the study, the duration (minutes) and the intensity of each training session were recorded for every player. Each participant's global perception intensity was rated on a modified Borg's category ratio scale ${ }^{[7]}$ approximately 30-min after each session. Briefly, training load from each session for each player was calculated from the product of the session duration and the player's perception of global training intensity (i.e. duration $\times$ intensity). The training monotony was also calculated from the average daily TL divided by the standard deviation of the daily training load calculated over a week. The weekly training strain was then calculated as the product of weekly training load and monotony. The mean training load and strain were also calculated for the 6-week IR and the 2-week RT.

\section{Short questionnaire of fatigue:}

The short questionnaire of fatigue as previously described ${ }^{[12]}$, consists of eight questions which focus on the following items: perception of training, sleep, leg pain, infection, concentration, efficacy, anxiety, irritability, and general stress. Each question was assessed on a 7-point scale: from not at all (1 point) to very much (7 points) (Table 1).

The responses to the questions were summed to obtain the total score of fatigue (TSF). All the questions played an important part in the TSF. The TSF was weighed and calculated according to the relative importance of each question in the score ${ }^{[12]}$. The lower the score, the better the perception of general well-being. The higher the score, the higher the perception of fatigue. The participants' variability of the TSF assessed in sixteen $7 \mathrm{~s}$ rugby players from the coefficient of variation of difference between double measurements within half a day was $2.1 \%$. The TSF during the 6-week IT and the 2-week RT were averaged in order to assess the relationship between this variable and the average values of training load, monotony, and strain recorded during these two periods.

\section{Training:}

The training program consisted of 6-week intense training (IT) or overload, and of 2 -week reduced

Table 1: Description of the eight items of the short questionnaire of fatigue

\begin{tabular}{|c|c|c|c|c|c|c|c|c|}
\hline & \multirow{2}{*}{$\begin{array}{l}\text { During the preceding week : } \\
\text { I found training more difficult than usual }\end{array}$} & \multicolumn{2}{|c|}{ Not at all } & \multicolumn{2}{|c|}{ Normal } & \multicolumn{3}{|c|}{ Very Much } \\
\hline 1 & & 1 & 2 & 3 & 4 & 5 & 6 & 7 \\
\hline 2 & I slept more & 1 & 2 & 3 & 4 & 5 & 6 & 7 \\
\hline 3 & My legs felt heavy & 1 & 2 & 3 & 4 & 5 & 6 & 7 \\
\hline 4 & I got caught cold/infection/flu & 1 & 2 & 3 & 4 & 5 & 6 & 7 \\
\hline 5 & My concentration was poorer than usual & 1 & 2 & 3 & 4 & 5 & 6 & 7 \\
\hline 6 & I worked less efficiency than usual & 1 & 2 & 3 & 4 & 5 & 6 & 7 \\
\hline 7 & I felt more anxious or irritable than usual & 1 & 2 & 3 & 4 & 5 & 6 & 7 \\
\hline 8 & I had more stress at home/school/training/work & 1 & 2 & 3 & 4 & 5 & 6 & 7 \\
\hline
\end{tabular}


training (RT) or taper. Of the 6-9 weekly training sessions, 2 focused on the development of the physical conditioning of the players. The work during these sessions was focused on the improvement of the aerobic capacity. Therefore, players performed highintensity interval runs, physical-technical circuits, and game-like activities with small groups and large spaces, with the intent that the intensity during the 4 to 6 minute series was very high. The intensity and duration of sessions gradually increased during the period of IT and declined steadily during the period of RT. Sessions of speed and coordination have also been performed by the players. During these sessions, speed and agility and coordination circuits had been set to improve sprinting performance, agility and coordination, respectively. The training was completed by 2 specific-strength training sessions in the gymnasium (duration of 30-45 minutes) before the field training. Strength training was developed using essential exercises such as squat and overhead split squat with or without external loads, box crossover and box jump, push-ups, draw chest, bench and inclined bench presses, abdominals and a variety of plyometric exercises for developing force-velocity of both lower and upper limbs ${ }^{[21]}$.

\section{Statistical analyses:}

Data are presented as mean \pm SD. One-way, repeated ANOVA tests were performed to check the differences between the three assessments (T0, T1, T2). When the differences were significant the $\mathrm{F}$ test was followed in post hoc procedure (Fisher's PLSD test). Correlation between training load and strain, physical performances, and scores of fatigue were calculated from linear regression. Correlations were retained only when the significance scores were confirmed using a Spearman non-parametric test. Intra-class correlation coefficients (ICCs) and standard error of measurement
(SEM) were calculated to evaluate the reliability of all physical performance assessments. Effect sizes (ES) were also calculated and reported (small $<0.4$, moderate $=0.4-0.70$, large $>0.70)^{[22]}$. Statistical analyses were performed using SPSS packages (SPSS Inc., Chicago, IL, version. 16.0) and the level of significance was set at $\mathrm{p} \leq 0.05$.

\section{RESULTS}

\section{Anthropometric and physical data:}

The anthropometric and physical characteristics of the rugby players through the training program are summarized in table 2 .

The training program, in both periods (IT and RT), was associated with a significant decrease of body mass, BMI and fat mass percentage. The lean body mass slightly but not significantly increased throughout the training period. All testing performances are presented in table 3 .

After the IT period (T1), all performances significantly decreased. Conversely, the RT (T2) generated a significant increase in all testing performances. The effect size of the population was large for both anthropometric (0.70-2.00; table 2) and testing performances parameters (0.84-1.10; table 2$)$.

\section{Training load, strain and total score of fatigue:}

The training load, monotony, strain and volume as well as the total score of fatigue are reported in table 4.

Training loads, monotonies, strains and volumes increased until reaching a maximum value for the 5 th week during the 6-week IT period. This increase was associated with simultaneous increased values of the total score of fatigue with the highest score recorded in

Table 2: Anthropometric variations over the 8-week training period

$\begin{array}{lcccc}\text { Measures } & \text { T0 }(\mathbf{n}=\mathbf{1 6}) & \text { T1 }(\mathbf{n}=\mathbf{1 6}) & \text { T2 }(\mathbf{n}=\mathbf{1 6}) & \text { Effect size } \\ \text { Age }(\text { year) } & 23.8(3.1) & - & - & - \\ \text { Height (cm) } & 183.1(0.1) & - & - & - \\ \text { Body mass (kg) } & 87.3(7.4) & 85.7(7.0)^{*} & 85.8(7.2)^{*} & 1.84 \\ \text { Fat mass (\%) } & 13.1(2.7) & 11.3(2.4)^{*} & 11.2(2.5)^{*} & 2.00 \\ \text { Lean mass (kg) } & 75.9(6.1) & 76.0(6.2) & 76.1(6.4) & 0.70 \\ \left.\text { Body mass index (kg.m }{ }^{-2}\right) & 26.1(2.4) & 25.6(2.2)^{*} & 25.6(2.5) & 1.81 \\ \quad *: \text { different than T0 }(P<0.05) & & & & \end{array}$


Table 3: Physical performance variations over the 8-week training period

\begin{tabular}{|c|c|c|c|c|}
\hline Measures & T0 $(n=16)$ & T1 $(n=16)$ & T2 $(n=16)$ & Effect size \\
\hline 10-m sprint (s) & $1.82(0.07)$ & $1.86(0.06)^{*}$ & $1.80(0.07)^{\S \dagger \dagger}$ & 0.93 \\
\hline 20-m sprint (s) & $3.12(0.07)$ & $3.16(0.08)^{*}$ & $3.09(0.07)^{8 \dagger \dagger}$ & 0.91 \\
\hline 30-m sprint (s) & $4.29(0.14)$ & $4.39(0.13)^{*}$ & $4.28(0.12)^{\dagger}$ & 0.98 \\
\hline Agility test (s) & $16.72(0.34)$ & $17.12(0.35)^{*}$ & $16.34(0.39)^{8 \dagger \dagger}$ & 0.84 \\
\hline Five-jump test (m) & $11.6(0.6)$ & $11.39(0.50)^{*}$ & $12.7(0.9) \S \S b$ & 0.91 \\
\hline Lactic test (m) & $709.1(36.6)$ & $702.3(35.1)^{*}$ & $727.1(30.1)^{\S \S \dagger \dagger}$ & 1.10 \\
\hline Yo-Yo IRT2 (m) & $1730.0(314.8)$ & $1625.0(312.5)^{*}$ & $1925.0(332.7)^{\S \S \dagger \dagger}$ & 0.95 \\
\hline
\end{tabular}

Yo-Yo IRT2: Yo-Yo intermittent recovery test level 2

*: different than T0 $(P<0.05) / / \S$ : different than T0; § $P<0.05$, §§ $P<0.01 / / \uparrow$ : different than $\mathrm{T} 1 ; \dagger P<0.05, \dagger \dagger P<0.001$

the 5th week. Conversely, all the parameters decreased significantly during the 2-week RT. Figures 2A-C, shows the mean training load and strain as well as the mean fatigue score recorded during the 6-week IT and the 2-week RT periods. Both training load and strain decreased significantly during the RT.

The mean score of fatigue followed the same timecourse as the training load and strain with lower values recorded during the period of RT.

\section{Training load and strain/score of fatigue correlations}

Over the two training periods, several correlations have been found between the mean training load, strain and the mean questionnaire fatigue score. The mean TSF was significantly correlated with the mean TL and TS recorded during the 6-week IT. The mean TSF was also significantly correlated with the mean TL and the mean TS recorded during the 2-week RT (Table 5).

\section{Physical performances/scores of fatigue correlations:}

Table 5 also shows several correlations between the mean TSF and the variation in percentage of some physical performances over the training program. The mean TSF was significantly correlated with the variation in percentage of the Yo-Yo IRT2 and the agility test performances recorded during the 6-week IT. The mean TSF was also significantly correlated with the percent variation of the lactic test, the agility test and 5JT performances recorded during the 2 -week RT.

\section{DISCUSSION}

The purpose of this study was to assess whether an 8item questionnaire of fatigue could be used to monitor changes in perceived training load and strain and physical performance during preparation for major competition among elite $7 \mathrm{~s}$ rugby players. This study showed that training load (TL) and training strain (TS)

Table 4: Training load, monotony, strain, total score of fatigue and frequency recorded over the 8-week training program

\begin{tabular}{|c|c|c|c|c|c|c|c|c|}
\hline \multirow{2}{*}{ Measures } & \multicolumn{6}{|c|}{ Intense Training } & \multicolumn{2}{|c|}{ Reduced Training } \\
\hline & Week 1 & Week 2 & Week 3 & Week 4 & Week 5 & Week 6 & Week 7 & Week 8 \\
\hline Training load (AU) & $\begin{array}{l}1326.3 \\
(104.7)\end{array}$ & $\begin{array}{c}1601.5 \\
(119.9)^{\S}\end{array}$ & $\begin{array}{c}1970.0 \\
(230.0)^{\S}\end{array}$ & $\begin{array}{l}1935.9 \\
(149.6)\end{array}$ & $\begin{array}{c}2782.7 \\
(155.1)^{\S \S}\end{array}$ & $\begin{array}{l}2785.9 \\
(236.5)\end{array}$ & $\begin{array}{l}2153.8 \\
(265.0)^{* *}\end{array}$ & $\begin{array}{c}1763.9 \\
(193.1)^{*}\end{array}$ \\
\hline $\begin{array}{l}\text { Training monotony } \\
\text { (AU) }\end{array}$ & $\begin{array}{c}0.81 \\
(0.05)\end{array}$ & $\begin{array}{c}1.09 \\
(0.06)\end{array}$ & $\begin{array}{c}1.11 \\
(0.07)\end{array}$ & $\begin{array}{c}0.97 \\
(0.05)\end{array}$ & $\begin{array}{c}1.66 \\
(0.11)\end{array}$ & $\begin{array}{c}1.14 \\
(0.05)\end{array}$ & $\begin{array}{c}0.95 \\
(0.03)\end{array}$ & $\begin{array}{c}0.92 \\
(0.05)\end{array}$ \\
\hline Training strain (AU) & $\begin{array}{l}1077.4 \\
(115.1)\end{array}$ & $\begin{array}{c}1747 \\
(191.2) \S \S\end{array}$ & $\begin{array}{c}2181.2 \\
(259.2)^{\S \S}\end{array}$ & $\begin{array}{l}1887.2 \\
(174.5)^{*}\end{array}$ & $\begin{array}{c}4613.0 \\
(418.2)^{\S \S \S}\end{array}$ & $\begin{array}{l}3161.8 \\
(257.4)^{* *}\end{array}$ & $\begin{array}{l}2055.4 \\
(274.4)^{* *}\end{array}$ & $\begin{array}{c}1613.3 \\
(148.5)^{* *}\end{array}$ \\
\hline $\begin{array}{l}\text { Total score of fatigue } \\
\text { (AU) }\end{array}$ & $\begin{array}{l}15.1 \\
(2.0)\end{array}$ & $\begin{array}{c}18.1 \\
(1.7)^{\S \S}\end{array}$ & $\begin{array}{c}19.1 \\
(1.6)^{\S}\end{array}$ & $\begin{array}{l}21.3 \\
(2.0)^{\S}\end{array}$ & $\begin{array}{c}22.8 \\
(1.6)^{\S}\end{array}$ & $\begin{array}{l}22.1 \\
(1.5)\end{array}$ & $\begin{array}{l}15.8 \\
(1.9)^{* *}\end{array}$ & $\begin{array}{l}13.1 \\
(1.9)^{* *}\end{array}$ \\
\hline $\begin{array}{l}\text { Session frequency } \\
\text { (n/week) }\end{array}$ & 6 & 7 & 8 & 7 & 9 & 8 & 6 & 7 \\
\hline $\begin{array}{l}\text { Weekly volume } \\
\text { (min) }\end{array}$ & 390 & 438 & 501 & 435 & 575 & 620 & 455 & 415 \\
\hline
\end{tabular}

$\S$ : higher than the precedent value; $\S P<0.05, \S \S P<0.01, \S \S \S P<0.001$; *: lower than the precedent value; * $P<0.05,{ }^{* *} P<0.01$ 

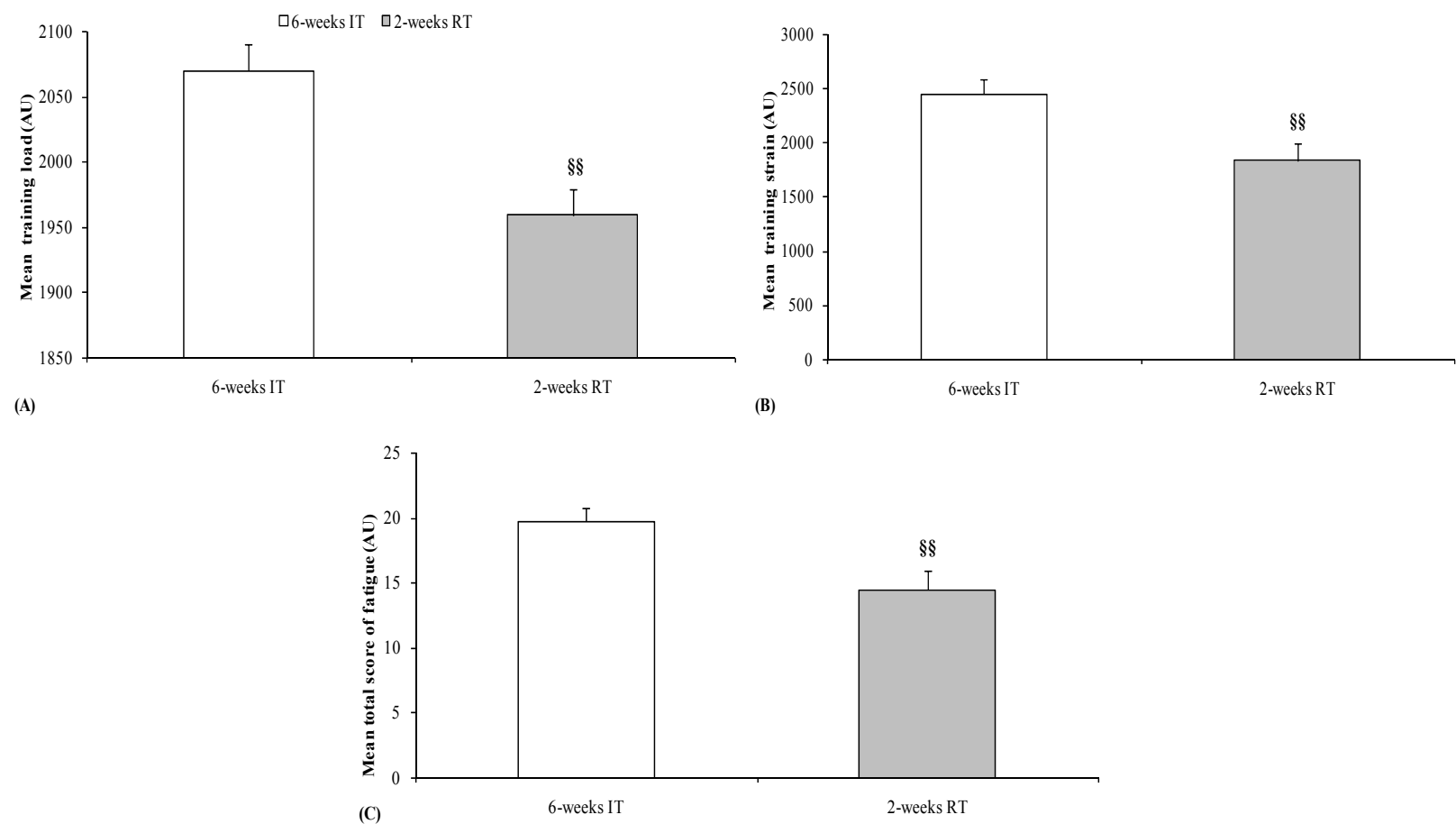

increased significantly during the intense training period and were associated with an increasing total score of fatigue (TSF) resulting in a decrease of all tested performances. In contrast, the TL and TS decreased significantly during the reduced training period leading to a decrease of the TSF and reciprocally an increase of the majority of physical performances. Furthermore, several relationships were found between the mean of TSF and the mean of TL and TS as well as the variation in percentage of some physical performance over the training period.

It is largely admitted that the improvement and maintenance of the physical performance is faced as a delicate and complex psychophysiological process, especially in highly trained athletes ${ }^{[11]}$. It is based on the periodization workouts and requires training sessions of which the volume and the intensity are crucial determinants ${ }^{[23,24]}$. When prolonged excessive

Table 5: Correlation between changes in different parameters during the two periods of training program

\begin{tabular}{|c|c|c|c|c|c|c|c|c|}
\hline T1 vs T0 & $\begin{array}{l}\text { TL of 6- } \\
\text { week IT }\end{array}$ & $\begin{array}{c}\text { TS of 6-week } \\
\text { IT }\end{array}$ & $\begin{array}{l}\text { TSF of 6- } \\
\text { week IT }\end{array}$ & $\begin{array}{l}\Delta 10 \mathrm{~m} \\
\text { sprint }\end{array}$ & $\Delta \mathrm{LT}$ & $\begin{array}{c}\Delta \mathrm{Yo}_{0}-\mathrm{Y}_{0} \\
\text { IRT2 }\end{array}$ & $\triangle \mathrm{AGT}$ & $\Delta \mathbf{5 J T}$ \\
\hline TL of 6-week IT & 1 & $r=0.78^{t}$ & $r=0.83^{\dagger}$ & $r=0.52^{*}$ & $r=0.54^{*}$ & $r=0.70^{+}$ & $r=0.59^{*}$ & $r=0.52^{*}$ \\
\hline TS of 6-week IT & - & 1 & $r=0.68^{\ddagger}$ & $r=0.31$ & $r=0.55^{*}$ & $r=0.64^{\ddagger}$ & $r=0.29$ & $r=0.53^{*}$ \\
\hline TSF of 6-week IT & - & - & 1 & $r=0.44$ & $r=0.45$ & $r=0.52^{*}$ & $r=0.63^{*}$ & $r=0.45$ \\
\hline T2 vs T0 & $\begin{array}{l}\text { TL of 2- } \\
\text { week RT }\end{array}$ & $\begin{array}{c}\text { TS of 2-week } \\
\text { RT }\end{array}$ & $\begin{array}{l}\text { TSF of } 2- \\
\text { week RT }\end{array}$ & $\begin{array}{l}\Delta 10 \mathrm{~m} \\
\text { sprint }\end{array}$ & $\Delta \mathrm{LT}$ & $\begin{array}{c}\Delta Y_{0}-Y_{0} \\
\text { IRT2 }\end{array}$ & $\triangle \mathrm{AGT}$ & $\Delta 5 \mathrm{JT}$ \\
\hline TL of 2-week RT & 1 & $r=0.97^{\dagger}$ & $r=0.68^{t}$ & $r=0.21$ & $r=0.68^{\ddagger}$ & $r=0.52^{*}$ & $r=0.62^{+}$ & $r=071^{*}$ \\
\hline TS of 2-week RT & - & 1 & $r=0.63^{+}$ & $r=0.22$ & $r=0.63^{\ddagger}$ & $r=0.39$ & $r=0.66^{\ddagger}$ & $r=0.63^{\ddagger}$ \\
\hline TSF of 2-week RT & - & - & 1 & $r=0.05$ & $r=0.51^{*}$ & $r=0.20$ & $r=0.56^{*}$ & $r=0.52^{*}$ \\
\hline
\end{tabular}

Legend: TL: Training load; TS: Training Strain; TSF: Total score of fatigue; IT: Intense training; RT: Reduced training; LT: lactic test; Yo-Yo IRT2: Yo-Yo intermittent recovery test level 2; AGT: agility test; 5JT: five-jump test; $\Delta$ : variation in percentage.

$* P<0.05 ; \ddagger P<0.01 ; \dagger P<0.001$ 
training stresses are applied, concurrently with inadequate recovery, many of the positive physiological adjustments associated with physical training are reversed possibly leading to overreaching or even overtraining ${ }^{[5,25]}$. To prevent overtraining and to ensure that the athletic training program is resulting in performance improvement or at least the maintenance of performance standards, it is necessary to monitor the training load and to include regular performance tests as a component of the training program ${ }^{[26]}$. Until recently, it has been very difficult to quantify the training loads completed by team-sport athletes such as rugby players due to difficulty in measuring the various types of stress encountered during training ${ }^{[4]}$. Moreover, each athlete may react differently to the same training load; consequently it is necessary to individualize the state of tiredness. Additionally, in rugby, a sport characterized by contact, impact and wrestle drills, with a lot of resistance and anaerobic efforts it is difficult and mostly inappropriate to use heart rate monitors during training sessions. Fortunately however, in the last decade the session-RPE method for quantifying training has become a popular tool for monitoring training periodization in various sports ${ }^{[7]}$, and several investigators have adopted this approach ${ }^{[7,9,10]}$. In the present study, we used the session-RPE method, owing to its simplicity, costlessness and its validity in various sport activities such as soccer, rugby union, basket-ball and other individual sports ${ }^{[7,9,10]}$. The physical training program of the current study was specifically designed to progressively overload the players during the initial 6 weeks. Consequently, the TL and TS progressively increased during this period by increasing training volume and frequency leading to significant increased TSF. Alongside these findings, there was a significant decrease in all tested physical performances. Collectively, the effects of increased training loads and strains across various training program periods are predisposing factors to homeostatic disruption and ultimately to performance impairment ${ }^{[13,14]}$. In this context, Coutts et $\mathrm{al}^{[9]}$ reported in seven semiprofessional rugby league players a decrease in muscular strength, power, and endurance during 6week overload training. In other team-sports, Kraemer et al ${ }^{[27]}$ observed reduced physical performances in professional soccer players with the advancement of the season. In the latter studies, physical power decrements were associated with physical fatigue resulting from the increase in training loads. Coutts et al ${ }^{[9]}$ stated that the most likely explanation for the decreased performance is increased muscle damage via a decrease in the anabolic-catabolic balance. Indeed, it is likely that the physical decrement observed in the present study could be explained by the fatigue state generated by the increased training load and strain which led to a catabolic state. In this regard, we report an average TSF of 20 units during the IT period which is consistent with the results of Atlaoui et al ${ }^{[15]}$ in highly trained swimmers. In this context, the three last weeks of the IT were associated with TSF scores over 20 units. Additionally, several relationships were found between the mean TSF and the variation in percentage of some physical performances recorded during the IT period. Moreover, the main result of the current study is the relationship between the mean of TL, TS and the TSF recorded during this period. The parallelism between the higher TSF, which reflects the perception of training, sleep, leg pain, infection, concentration, efficacy, anxiety, irritability, and general stress, and the higher TL and TS, which were associated with physical performance decrements, means that the questionnaire of fatigue is a sensitive tool for the variations of perceived training load and strain. The present results are consistent with the conclusions previously reported by Chatard et al ${ }^{[12]}$ and Atlaoui et $\mathrm{al}^{[15]}$ suggesting that the questionnaire of fatigue is sensitive to changes in training stress, load and strain in elite athletes. Similarly, the reduced training period was characterized by a decrease of TL and TS which was associated with a decrease in TSF and reciprocally an increase of the majority of physical performances. Studying highly trained athletes, it has been reported ${ }^{[28]}$ better physiological and performance outcomes with low-volume than with moderate-volume tapers. Bosquet et al ${ }^{[29]}$ determined through their metaanalysis that performance improvement during the taper was highly sensitive to the reduction in training volume. These authors described a dose-response relationship between the duration of the taper and the performance improvement and suggest that a 2-week taper during which training volume is exponentially reduced by $41-60 \%$ to be the most efficient strategy to maximize performance gains. In agreement with the conclusion of the latter study, the weekly duration of training sessions decreased by $33 \%$ compared to pre- 
taper value (415 min vs. $620 \mathrm{~min}$ ) over the 2-week period which could explain the more important increase of the majority of physical performances observed in our rugby $7 \mathrm{~s}$ players compared to those observed by Coutts et al ${ }^{[9]}$ and Coutts and Reaburn ${ }^{[13]}$ in the same population of rugby union players during a shorter period with decreases of volume of $50 \%$. Consequently, based on the present results and those developed by Bosquet et al ${ }^{[29]}$, it seems that a 2 -week tapering period preceding major competition is the better strategy to maximize performance gains in elite rugby $7 \mathrm{~s}$ players through physiological and psychological states optimization. Although, training loads and strains of the RT period were higher than those recorded during the first two-weeks of the program, the present study's subjects perceived the training stress with less intensity; hence, they reported a mean TSF under 15 units over this period reflecting consequently a positive adaptive response objectified by enhanced physical performances. Additionally, the relationship between the mean TL and TS and the mean TSF during this period strengthens the reliability of the short questionnaire of fatigue as a sensitive and practical tool for monitoring training load and strain and changes in athletic performance. Nevertheless, our study presents some limitations. It would be interesting to associate these analyses with physiological parameters such as anabolic and catabolic hormone levels. This will especially aid indication of the catabolic/anabolic status of the athletes leading to prevent possible states of fatigue or overtraining. On the other hand, the short questionnaire of fatigue allows a complementary assessment of training stress, load, anxiety and strain in athletes which are determinant factors of performances.

\section{CONCLUSION}

In summary, this study showed that the short questionnaire of fatigue was sensitive to changes in training load and physical performances throughout the whole training period. These findings strengthen the interest of the questionnaire of fatigue as a simple, costless and useful tool for monitoring perceived training load and strain in high level athletes. Using both session-RPE and questionnaire method for monitoring training may consequently help coaches to control training stimuli and prevent eventual states of stainless and/or overtraining.

\section{ACKNOWLEDGMENTS}

Authors would like to express their gratitude to players, coaches and manager of Tunisia Sevens National Team for their cooperation. Additionally, the present study has been performed thanks to Tunisia Rugby Union. This study was financially supported by the Tunisian Ministry of High Education and Scientific Research.

\section{Conflict of interests: None}

\section{REFERENCES}

1. Duthie G, Pyne D, Hooper S. Applied physiology and game analysis of rugby union. Sports Med 2003;33:973-91.

2. Gabbett TJ. Physiological characteristics of junior and senior rugby league players. Br J Sports Med 2002;36:334-9.

3. Takahashi I, Umeda T, Mashiko T, et al. Effects of rugby sevens matches on human neutrophil-related non-specific immunity. Br $J$ Sports Med 2007;41:13-8.

4. Argus CK, Gill N, Keogh J, et al. Effects of a short-term pre-season training programme on the body composition and anaerobic performance of professional rugby union players. J Sports Sci 2010;28:679-86.

5. Meeusen R, Nederhof E, Buyse L, et al. Diagnosing overtraining in athletes using the two-bout exercise protocol. Br $J$ Sports Med 2010;44:642-8.

6. Armstrong LE, VanHeest JL. The unknown mechanism of the overtraining syndrome: clues from depression and psychoneuroimmunology. Sports Med 2002;32:185-209. 
7. Foster C, Florhaug JA, Franklin J, et al. A new approach to monitoring exercise training. J Strength Cond Res 2001;15:109-15.

8. Bangsbo J, Mohr M, Krustrup P. Physical and metabolic demands of training and match-play in the elite football player. J Sports Sci 2006;24:665-74.

9. Coutts A, Reaburn P, Piva TJ, Murphy A. Changes in selected biochemical, muscular strength, power, and endurance measures during deliberate overreaching and tapering in rugby league players. Int J Sports Med 2007;28:116-24.

10. Haddad M, Chaouachi A, Castagna C, et al. The construct validity of session RPE during an intensive camp in young male Taekwondo athletes. Int J Sports Physiol Perform 2011;6:252-63.

11. Kellmann M. Preventing overtraining in athletes in high-intensity sports and stress/recovery monitoring. Scand J Med Sci Sports 2010;20:95-102.

12. Chatard JC, Atlaoui D, Pichot V, et al. Training follow up by questionnaire fatigue, hormones and heart rate variability measurements. Sci Sports 2003;18:302-4.

13. Coutts AJ, Reaburn P. Monitoring changes in rugby league players' perceived stress and recovery during intensified training. Percept Mot Skills 2008;106:904-16.

14. Elloumi M, Ben Ounis O, Tabka Z, et al. Psychoendocrine and physical performance responses in male Tunisian rugby players during an international competitive season. Aggress Behav 2008;34:623-32.

15. Atlaoui D, Duclos M, Gouarne C, et al. The 24-h urinary cortisol/cortisone ratio for monitoring training in elite swimmers. Med Sci Sports Exerc. 2004;36:218-24.

16. Durnin JV, Womersley J. Body fat assessed from total body density and its estimation from skinfold thickness: measurements on 481 men and women aged from 16 to 72 years. Br J Nutr. 1974;32:77-97.

17. Chaouachi A, Brughelli M, Levin G, et al. Anthropometric, physiological and performance characteristics of elite team-handball players. J Sports Sci. 2009;27:151-7.

18. Chamari K, Chaouachi A, Hambli M, et al. The five-jump test for distance as a field test to assess lower limb explosive power in soccer players. J Strength Cond Res. 2008;22:944-50.

19. Maso F, Cazorla G, Godemet M, et al. Physiological features of rugby players of French team. Sci Sports 2002;17:297-301.

20. Krustrup P, Mohr M, Nybo L, et al. The Yo-Yo IR2 test: physiological response, reliability, and application to elite soccer. Med Sci Sports Exerc 2006;38:1666-73.

21. Chelly MS, Ghenem MA, Abid K, et al. Effects of in-season short-term plyometric training program on leg power, jump- and sprint performance of soccer players. J Strength Cond Res 2010;24:2670-6.

22. Cohen J. Statistical Power Analysis for the Behavioral Science. $2^{\text {nd }}$ ed. Hillsdale, NJ: Lawrence Erlbaum Associates, 1988.

23. Gamble P. Periodization of training for team sport athletes. Strength Cond J 2006;28:55-6.

24. Issurin VB. New horizons for the methodology and physiology of training periodization. Sports Med 2010;40:189-206.

25. Lehmann M, Gastmann U, Petersen KG, et al. Training-overtraining: performance, and hormone levels, after a defined increase in training volume versus intensity in experienced middle- and long-distance runners. Br J Sports Med 1992;26:233-42.

26. Foster C, Daines E, Hector L, et al. Athletic performance in relation to training load. Wis Med J 1996;95:370-4.

27. Kraemer WJ, French DN, Paxton NJ, et al. Changes in exercise performance and hormonal concentrations over a big ten soccer season in starters and nonstarters. $J$ Strength Cond Res 2004;18:121-8.

28. Mujika I, Padilla S. Scientific bases for precompetition tapering strategies. Med Sci Sports Exerc 2003;35:1182-7.

29. Bosquet L, Montpetit J, Arvisais D, Mujika I. Effects of tapering on performance: a meta-analysis. Med Sci Sports Exerc 2007; 39:1358-65 